IOSR Journal of Pharmacy

e-ISSN: 2250-3013, p-ISSN: 2319-4219, www.iosrphr.org

Volume 2 Issue 6 || || Nov-Dec. 2012 ||| PP.01-04

\title{
Sex related difference in response to experimental pain in first year medical students
}

\author{
Samir Mendpara ${ }^{1}$ Veena Jasuja ${ }^{2}$ Geetanjali Purohit ${ }^{3}$ \\ BM Palan ${ }^{4}$ JM Harsoda $^{5}$ \\ ${ }^{1}$ Dr.Samir Mendpara (Resident doctor in Physiology) \\ ${ }^{2}$ Dr. Veena Jasuja (Tutor in Physiology) \\ ${ }^{3}$ Ms. Geetanjali Purohit: (Tutor in Physiology) \\ ${ }^{4}$ Dr. BM Palan: (Associate Professor in Physiology) \\ ${ }^{5}$ Dr.JM Harsoda: (Prof \& Head in Physiology) \\ SBKS MI \& RC, Sumandeep Vidyapeeth, Vadodara, Gujarat
}

\begin{abstract}
Pain is complex multidimensional experience influenced by physical, psychological, and social factors. In recent years sex differences in responses to pain have received increased attention. Purpose of study was to determine sex differences in experimental pain response. For this study cold pressor test was used to exert experimental pain. 100 medical students (50 boys and 50 girls) participated in study. Subject was asked to submit his hand into container with ice water. Radial pulse was measured before and immediately after test to determine pulse reactivity. Pain threshold and tolerance were measured. Subject was asked to determine intensity of pain during test and rate on VAS. Data was statistically analysed using student t-test and Correlation Coefficient. Pain threshold and pain tolerance were significantly more in boys, Pain rating was significantly more in girls. Pain reactivity was significantly more in girls. In both sexes, baseline pulse showed positive relationship with pain threshold and pain tolerance and negative relationship with pain rating. Women typically displaying greater pain sensitivity than men, but mechanisms underlying differences remain unclear. Possible explanation suggests that men are more motivated to tolerate and suppress expressions of pain because masculine sex role, whereas feminine sex role encourages pain expression. Different pain perception might account for sex difference in pulse reactivity. Hormonal influences may play minor role.
\end{abstract}

\section{INTRODUCTION}

Pain is the main reason for visiting the emergency department in more than $50 \%$ of cases and is present in $30 \%$ of family practice visits. Several epidemiological studies from different countries have reported widely varying prevalence rates for chronic pain, ranging from $12-80 \%$ of the population ${ }^{(1)}$.

The International Association for the Study of Pain's widely used definition states: "Pain is an unpleasant sensory and emotional experience associated with actual or potential tissue damage, or described in terms of such damage" ${ }^{(2)}$.

Pain is a complex multidimensional experience influenced by physical, psychological, and social factors. In recent years sex differences in responses to pain have received increased attention. Multiple studies have investigated sex differences in experimental pain perception using a wide variety of noxious stimuli ${ }^{(3)}$.

For this study, the cold pressor test was used to exert experimental pain. The cold pressor test (CPT) is an empirically validated test commonly used in research on stress, pain and cardiovascular reactivity. George E. Brown and Edgar A. Hines in 1932 introduced a test designed to detect latent states of hypertension by immersion of one extremity in ice water for 1-3 minutes. This test was called as Hines and Brown test. Later on name of this test was changed to cold pressor test. Cold pressure test is simple, provocative, non-invasive, reliable and cheap test to know autonomic status of body ${ }^{(4)}$.

If variation in response to experimental pain according to age, sex, race etc, is studied, it is quite possible that more effective analgesia could be developed on the basis of these differences.

\section{AIM AND OBJECTIVE}

The purpose of this study was to determine sex differences in experimental pain response. For this study pain threshold, pain tolerance and pain rating as three pain sensitivity parameters and radial pulse as cardiovascular parameter were selected to study the response of experimental pain. 


\section{MATERIALS \& METHODS}

Total 100 young volunteers, medical students of S.B.K.S. medical college and research centre participated as subject in this study. 100 students were taken in two groups. First was group of 50 male students and second was group of 50 female students. The present study was conducted in clinical laboratory, Department of Physiology, S.B.K.S. medical college. Written informed consent was obtained according to ethical committee policy. On the day of testing, the subject signed an consent form acknowledging their willingness to participate in the study. Before testing, every subject was interviewed for recent history and examined for respiratory disease and cardio-vascular disease and subjects with such type of diseases were excluded from the study. Person taking analgesic for pain relief was excluded from the study.

Subjects were asked to sit comfortably in chairs. After rest for around 10 minutes, resting radial pulse was counted for one minute and recorded as rate per minute. Laboratory water bath was filled with ice cold water and temperature of cold water was measured using laboratory thermometer. Temperature of cold water was maintained between $4^{\circ} \mathrm{C}$ to $8^{\circ} \mathrm{C}$ by adding required ice cold water to the container ${ }^{(5)}$.

After that, subject was asked to submit his/her dominant hand into a container with ice water (palm down, up to $5 \mathrm{~cm}$ above wrist level). Immediately, two stop watches were started. Subject was asked to determine intensity of pain during test and rate it on a scale of 0 to 10 and for that subject was explained that Zero represents no pain at all while 10 represents the worst imaginable pain ${ }^{(6)}$. Subject was explained that once pain was present during test, they let the researcher know. One stop watch was stopped. This provided pain threshold (first feeling pain). Once the pain was unbearable, the participant removed his/her hand, second stop watch was stopped and this provided pain tolerance. Immediately after test radial pulse rate per minute was measured.

Statistical analysis: Data was collected and statistical analysed using student $\mathrm{t}$ test and zero order correlation coefficient.

\section{OBSERVATION AND RESULTS}

Table 1: Difference in various parameters between male and female.

\begin{tabular}{|lllll|}
\hline Parameters & Male & Female & T value & P value \\
\hline Pulse (rate/min) & $78.94 \pm 7.05$ & $77.58 \pm 7.54$ & 0.98 & 0.35 \\
\hline Pulse reactivity & $7.0 \pm 6.25$ & $12.58 \pm 7.86$ & 3.92 & $0.0001^{* *}$ \\
\hline PTh (sec) & $22.72 \pm 8.96$ & $17.68 \pm 6.59$ & 3.2 & $0.001^{* *}$ \\
\hline PTo (sec) & $66.92 \pm 22.32$ & $50.98 \pm 15.40$ & 4.15 & $0.043^{*}$ \\
\hline PR (VAS) & $6.0 \pm 0.83$ & $6.58 \pm 0.90$ & 3.33 & $0.001^{* *}$ \\
\hline
\end{tabular}

Data is demonstrated in MEAN \pm SD. unpaired t-test, $\mathrm{df}: 98$

* Difference significant at $p<0.05 * *$ Difference highly significant at $p<0.01$

Pulse reactivity $=$ after CPT pulse - Baseline pulse.

PTh: pain threshold, PTo : pain tolerance, PR : pain rating on visual analog scale.

As per the above results, pain threshold was found to be significantly more in boys compare to girls (22.72 \pm 8.96 vs $17.68 \pm 6.59)$. Pain tolerance was also found to be significantly more in boys compare to girls $(66.92 \pm$ 22.32 vs $50.98 \pm 15.40$ ). While pain rating on visual analog scale was found to be significantly more in girls compare to boys $(6.58 \pm 0.90$ vs $6.0 \pm 0.83)$. There was no difference in baseline pulse between boys and girls while pulse reactivity was found to be significantly more in girls compare to boys (12.58 \pm 7.86 vs $7.0 \pm 6.25)$.

Chart 1: Difference in various parameters between male and female.

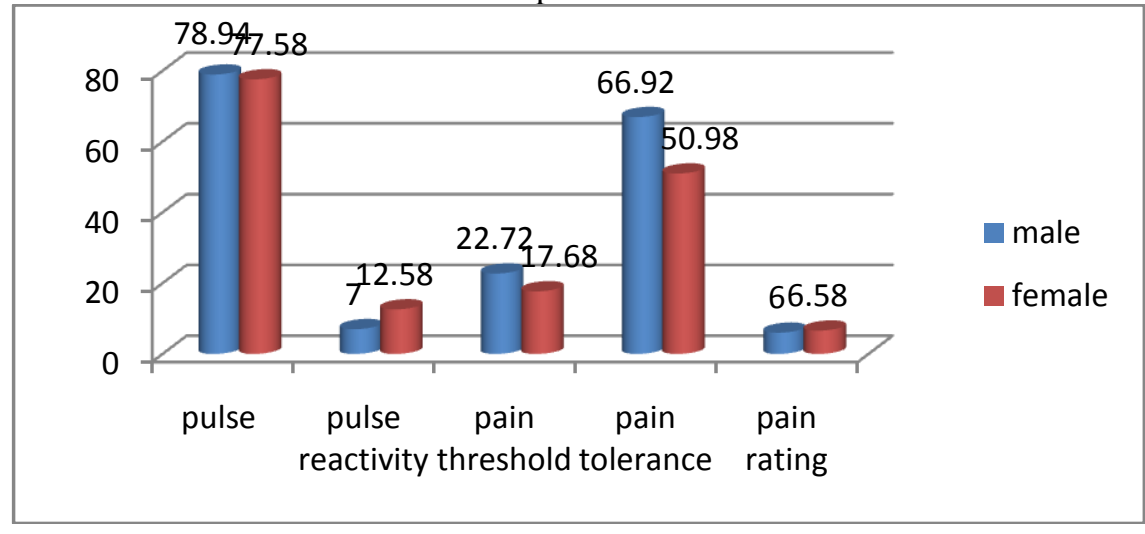


Data was also analysed by zero order correlation coefficient to determine relation between baseline pulse with pain sensitivity parameters and pulse reactivity with pain sensitivity parameters in both male and female.

Table 2: correlation coefficients in male data

\begin{tabular}{|llll|} 
Parameters & Pain threshold & Pain tolerance & Pain rating \\
Baseline Pulse & $\mathrm{r}=0.251$ & $\mathrm{r}=0.194$ & $\mathrm{r}=-0.069$ \\
& $\mathrm{p}=0.0787$ & $\mathrm{p}=0.1752$ & $\mathrm{p}=0.6317$ \\
\hline Pulse reactivity & $\mathrm{r}=-0.045$ & $\mathrm{r}=0.044$ & $\mathrm{r}=-0.227$ \\
& $\mathrm{p}=0.7539$ & $\mathrm{p}=0.7594$ & $\mathrm{p}=0.1127$ \\
\hline
\end{tabular}

Data demonstrate $\mathrm{r}$ value between parameters.

* Correlation significant at $\mathrm{p}<0.05$ (two-tailed)

Table 3: correlation coefficients in female data

\begin{tabular}{|llll|} 
Parameters & Pain threshold & Pain tolerance & Pain rating \\
& $\mathrm{r}=0.181$ & $\mathrm{r}=0.112$ & $\mathrm{r}=-0.133$ \\
& $\mathrm{p}=0.2085$ & $\mathrm{p}=0.4368$ & $\mathrm{p}=0.3540$ \\
\hline Pulse reactivity & $\mathrm{r}=-0.144$ & $\mathrm{r}=0.0086$ & $\mathrm{r}=-0.117$ \\
& $\mathrm{p}=0.3173$ & $\mathrm{p}=0.9522$ & $\mathrm{p}=0.4185$ \\
\hline
\end{tabular}

Data demonstrate $r$ value between parameters.

* Correlation significant at $\mathrm{p}<0.05$ (two-tailed)

As per the above results of table 2 and table 3, Baseline pulse was found to be positively correlated with pain threshold and pain tolerance in both sexes while negatively correlated with pain rating in both sexes. Second observation is that pulse reactivity was found to be positively correlated with pain tolerance in both sexes while negatively correlated with pain threshold and pain rating in both sexes. None of the correlations were found to be significant in this study.

Chart 2: correlation between baseline pulse and pain threshold in male and female

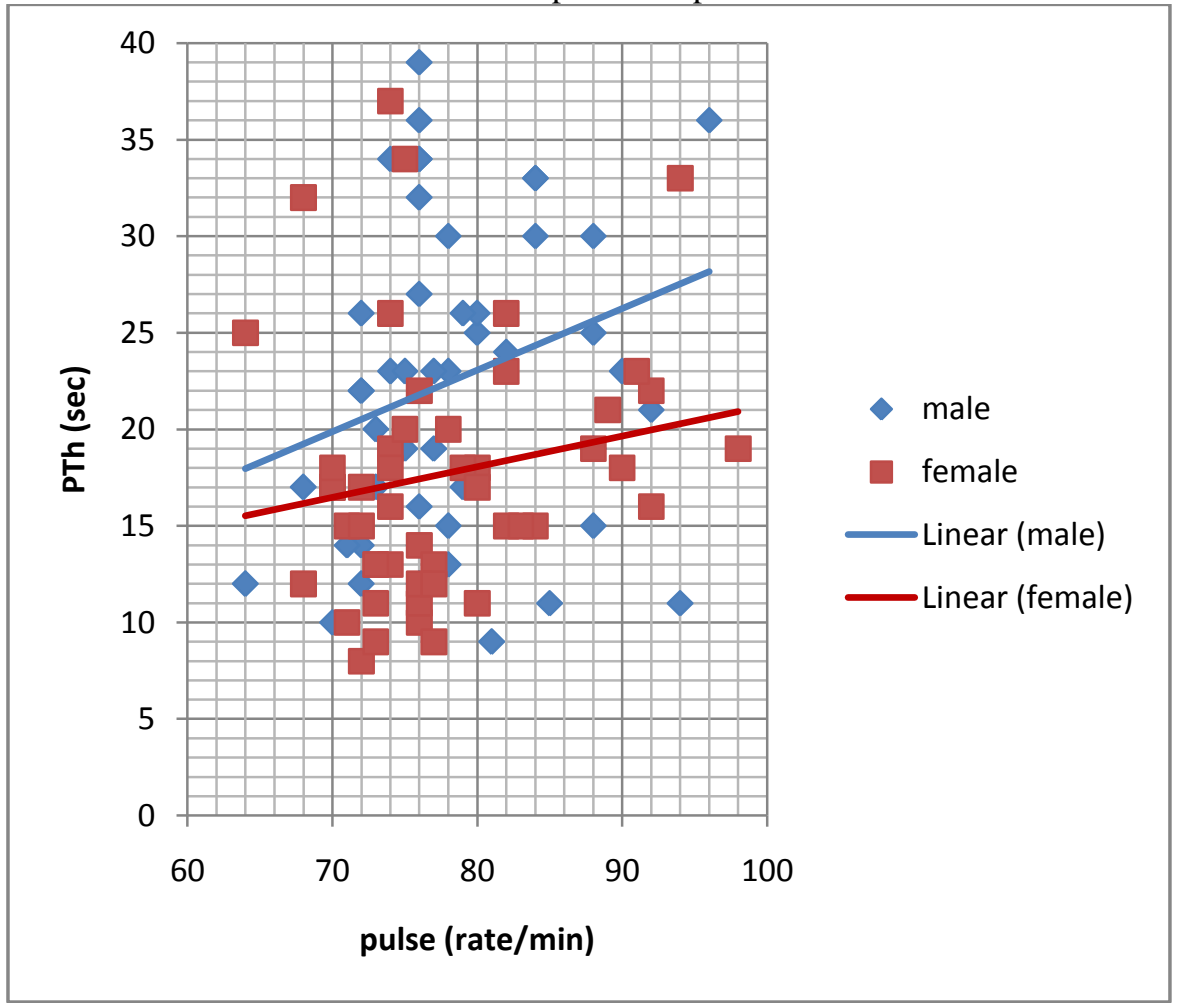


Chart 3: correlation between baseline pulse and pain tolerance in male and female

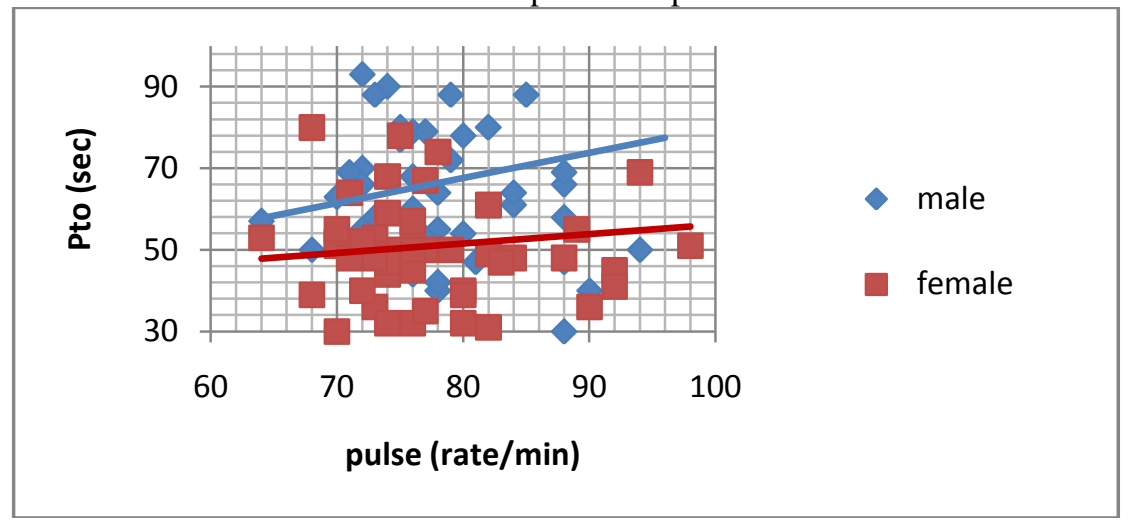

Chart 4: correlation between baseline pulse and pain rating in male and female

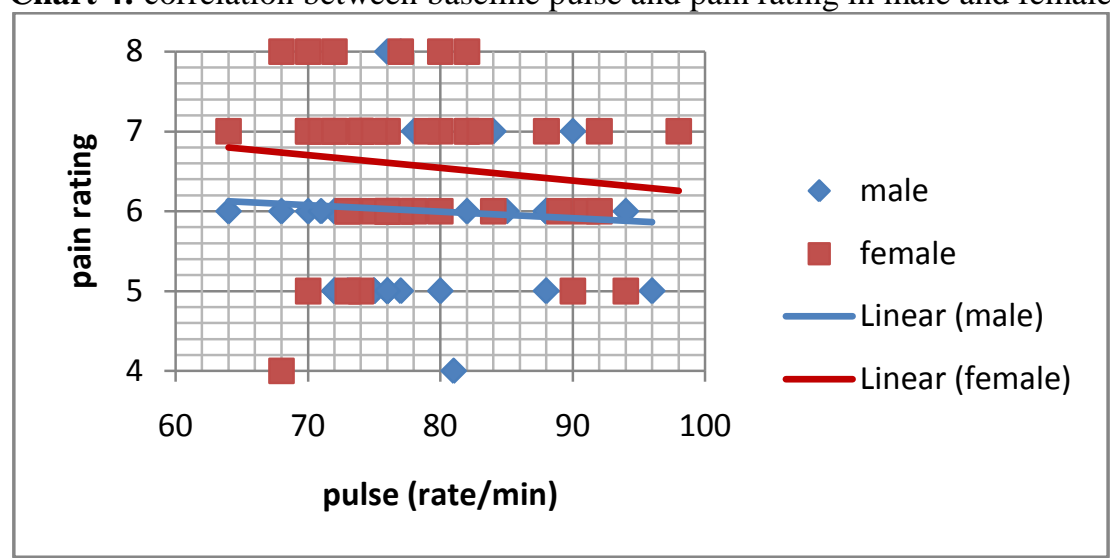

\section{DISCUSSION}

Women typically displaying greater pain sensitivity than men, but the mechanisms underlying these differences remain unclear. One possible explanation suggests that men are more motivated to tolerate and suppress expressions of pain because of the masculine sex role, whereas the feminine sex role encourages pain expression and produces lower motivation to tolerate pain among women ${ }^{(7)}$.

Other mechanisms have been proposed to explain the differing response to experimental pain between the sexes, including hormonal factors, differences in pain modulatory systems, and genetic factors. From a more psychosocial perspective, another potential explanation for the sex difference in pain responses involves social role expectancies. Different pain perception might account for sex difference in pulse reactivity. Hormonal influences may play a minor role ${ }^{(8)}$.

In this study, we found an insignificant inverse relationship between baseline pulse and pain sensitivity as indicated by pain threshold and pain tolerance. This relation was also found by Cynthia d. Myers et al. ${ }^{(7)}$, and Otto and Dougher in their studies ${ }^{(9)}$.

\section{REFERENCES}

[1]. Abu-Saad Huijer H. Chronic pain: A review. Leb Med J. 2010;58(1):21-27

[2]. IASP Sub-committee on Taxonomy. Pain terms: a list with definitions and notes on usage. Pain 1980; 8: 249-52.

[3]. Daniel lowery, ma, roger b. Fillingim, phd, and rex a. Wright, phd: sex differences and incentive effects on perceptual and cardiovascular responses to cold pressor pain. Psychosomatic medicine 65:284-291 (2003)

[4]. Ritesh M., Karia M. D., Mahavirsingh Rajput M. D., Hemant B., Mehta M. D., Pradnya A. and Gokhale M. D.: Normal Young Healthy Subjects: A Prediction of Future Possibilities of Hypertension. J Phys Pharm Adv 2012, 2(6): 223-226

[5]. Mitchell LA, MacDonald RA, Brodie EE: Temperature and the cold pressor test. J Pain 5:233-237, 2004

[6]. Dr. Muralidhar Joshi: Evaluation of pain. Indian J. Anaesth. 2006; 50 (5) : 335 - 339.

[7]. Cynthia d. Myers, phd, michael e. Robinson, phd, joseph 1. Riley iii, phd, and david sheffield, phd sex, gender, and blood pressure: contributions to experimental pain report psychosomatic medicine 63:545-550 (2001)

[8]. Berkley kj. Sex differences in pain. Behav brain sci 1997;20: 371-80.

[9]. Otto MW, Dougher MJ. Sex differences and personality factors in responsivity to pain, Percept Mot Skills 1985;61:383-90.

[10]. Woodrow KM, Friedman GD, Siegelaub AB, Collen MF. Pain tolerance: differences according to age, sex and race. Psychosom Med 1972; 34: 548-56. 